University of Massachusetts Amherst ScholarWorks@UMass Amherst

Published Work

Center for Student Success Research

2017

\title{
Geographic mobility and social inequality among Peruvian university students
}

\author{
Ryan S. Wells \\ University of Massachusetts Amherst \\ Ricardo Cuenca \\ Instituto de Estudios Peruanos \\ Gerardo Blanco Ramírez \\ University of Massachusetts Boston \\ Jorge Aragón \\ Instituto de Estudios Peruanos
}

Follow this and additional works at: https://scholarworks.umass.edu/cfssr_publishedwork

Part of the Higher Education Commons

\section{Recommended Citation}

Wells, Ryan S.; Cuenca, Ricardo; Blanco Ramírez, Gerardo; and Aragón, Jorge, "Geographic mobility and social inequality among Peruvian university students" (2017). Higher Education. 11.

https://doi.org/10.1007/s10734-017-0149-6 


\section{Geographic Mobility and Social Inequality among Peruvian University Students}

High quality educational opportunities are rarely distributed equally across geographies. Therefore, the social mobility that may result from education is likely to be linked to geographic mobility. Quite simply, more advantaged students are often more mobile and therefore can more readily take advantage of high quality educational opportunities even if far from home. Geographic mobility is often more likely for men, younger adults, and those who already moved in the past (Benavides and Etesse 2012; Bonin 2008). Such differences in mobility may help to maintain inequality of educational access. For example, there may simply be fewer opportunities for tertiary education when less mobile. Additionally, proximate tertiary choices may be of limited quality for those who are more geographically bound.

The connection between spatial inequality and social inequality is recognizable in many places, and yet most often overlooked in educational research. Without more robust studies examining geographic aspects of college going, a vital piece of the puzzle of educational inequality is missing. We aim to contribute to this needed conversation in regards to tertiary education. To do so, we use descriptive and correlational methods to analyze Peruvian university student census data. The specific purpose of this study is to explore geographic mobility among university students in Peru, and to understand how mobility patterns differ by region ${ }^{1}$ and by demographic indicators of inequality. While there is some high quality research on inequality in Peru (e.g., Cuenca, 2014a; Cuenca \& Reátegui, 2016), it is nonetheless an under-researched topic in an under-researched country, and is valuable in adding to knowledge about education in this location.

\footnotetext{
${ }^{1}$ We use the term "region" to represent the 26 administrative divisions in Peru -25 geographic regions, and the province of Lima. In addition, we combine the Provincia Constitucional del Callao with Lima for our analyses, giving us 25 "regions" for analysis.
} 
Complicating the picture of inequality and mobility in Peru, however, is a geography with an unequal distribution of universities, combined with existing economic and commercial routes that drive mobility in certain patterns. The sheer numbers of universities, as well as the quality of those institutions, is greater in some areas of the country than in others. Students in areas with fewer options and/or lower quality have little choice but to be mobile if they are to attend a high-quality university and realize the associated positive economic and social outcomes. While such mobility is most often an individual benefit, it can also distribute talent unequally if the educated follow specific geographic patterns (e.g., the commonly discussed phenomenon of brain drain). Thus, the interplay between individual characteristics associated with inequality, marginalized geographic areas, and the distribution of university education across those areas is complicated. There may simultaneously be factors discouraging and encouraging individuals to be geographically mobile for university education.

There is little previous research on these topics in Peru - and more generally in Latin America - and it is the nexus of these topics that we aim to explore. While our research is necessarily narrow and limited to Peru, the ways that the themes are likely to translate elsewhere, even when the specifics of the situation differ, make this research important for what may be learned more broadly and possibly adapted to other locations. The generative nature of our findings can inform future conceptual and empirical work on various marginalized populations worldwide, in rich and poor countries, in the global North and global South.

\section{Expansion and inequality in the Peruvian higher education context}

Along with most countries in Latin America, Peru began the expansion of its higher education system during the late 1980s. By the end of that decade, the region reached a postsecondary enrolment of $18.4 \%$. This growth constituted Peru's initial higher education 
massification process (Cuenca 2015a). In the Peruvian case, this expansion continued and intensified at the end of the 1990s. Many different factors contributed to such expansion.

The first contributing factor toward higher education massification in Peru was significant economic growth, of about $5.5 \%$ of GDP, during the 1990s. This growth had a positive impact on household incomes and, therefore, on the expenditure of families on the education of their children. Additionally during those years, the country experienced a demographic window, in which the economically active population grew at a faster rate than the non-economically active population. At the same time, opportunities for secondary and postsecondary education expanded and the State decreased its attention toward technical education. In 1996, the Peruvian government liberalized the educational market; this policy change allowed universities to profit (Cuenca 2014b). This move was aimed at incentivizing private investment in the higher education system and, subsequently, satisfying the growing demand for higher education.

The liberalization of higher education in Peru was based on a number of budgetary projections and a particular set of assumptions. It was assumed that the higher education liberalization process would increase the available offerings of higher education. Indeed, this growth took place. Between 1995 and 2014, higher education enrolment grew from 400,000 to $1,125,000$. This growth is attributed primarily to private higher education enrolments, which increased from 28\% to 70\% of higher education enrollments by 2014 (Cuenca 2015a).

It was expected that the expansion of higher education would democratize access. This, however, was not the case. Due in part of the privatized nature of the changing system, access to higher education remained as an option available primarily to youth whose families were in the highest income brackets. Access to higher education was not a possibility for those students in the lowest income tiers. Higher education access among low-income groups is around $10 \%$ in Peru, in contrast to $45 \%$ among the richest segments of the population 
(León and Sugimaru, 2013). Accounting for ethnicity, only 1\% of Amazonian indigenous youth enter higher education. Moreover, only $4 \%$ of women entering higher education are indigenous (Cuenca and Patiño 2014; Cuenca and Ramírez 2015). Importantly for this study, these high- and low-income groups are also not geographically distributed evenly, and correspondingly, neither are the opportunities for higher education. (See Table A1 in the Appendix for data regarding the total number of private and public universities and institutes in Peru, by region.)

The last assumption by government officials and policymakers in Peru in relation to higher education expansion was that the market would regulate quality. In certain national contexts, where the higher education systems are institutionalized, the market serves as a second order factor for regulating quality. However, in countries such as Peru, where the educational system has gone through a massification stage, the market by itself is not a guarantee for improving quality (Brunner 2011).

Although there are still some important gaps in evidence about the quality of higher education in Peru, the available data present a relatively clear picture.. For example, Peruvian universities do not appear in any world or regional ranking, the volume of research is incipient, the average academic level of teachers is basic, the employability of young people is low and both public and private universities invest very little in research and teaching. Further, quality factors also vary by region within Peru, due in part to the orientation of public policies focusing on access. The growth of the supply of institutions took place in a context where the market was unable by itself to provide a significant regulation. (Castro and Yamada 2013, Cuenca and Reategui 2016, Dargent and Chavez 2016, Garfias 2011). 
In sum, the Peruvian higher education system has expanded rapidly in recent years (León and Sugimaru 2013). This expansion is related to (a) higher demand among youth that have completed secondary education, and (b) increased supply of higher education (Yamada, Castro, Bacigalupo and Velarde 2013). Access to higher education did not increase proportionally for students at all income levels and across ethnicities, and the expansion of higher education did not happen with adequate quality control. The old formula, employed in elementary education, of first increasing enrolment and pursing quality later, did not work (Cuenca 2015a). This observation is particularly evident when taking a close look at social and educational inequality. Inequality indicators still reveal significant gaps between urban and rural settings and between indigenous and non-indigenous populations (de Belaunde, Trivelli and Israel 2011). (See Table A2 in the appendix for socioeconomic indicators in Peru, by region.) As such, inequality becomes horizontal: similar income groups experience vast differences depending on their setting (e.g., urban/rural) or their identity groups (e.g., indigenous/non-indigenous). In addition, the stratification of access to higher education by income and ethnicity suggests a spatial component, given a population that is geographically segregated by these factors. The ways that students may be able to move geographically in order to access quality higher education within this system can be a driver of equality or inequality, depending on who is able to take advantage.

\section{Geographic inequality and mobility in Peru}

The social and educational context of Peru is characterized by significant inequalities. Cuenca (2014) asserts that Peru is one of the most unequal countries in Latin America, which is in turn one of the most unequal regions of the globe. Benavides, León, Haag and Cueva (2015) argue that, despite the expansion and diversification of higher education in Peru, inequality has not declined. This phenomenon is likely due to the high selectivity of public universities, on one hand, and the lack of affordable private higher education on the other. 
These two trends reproduce inequality given that wealthier urban students are best equipped to succeed in the competitive admissions process required to enter public universities or can simply afford the cost of private education. As noted above, the higher education expansion has taken place to a great extent in the private sector (León and Sugimary 2013). In this sense, Peru's largely privatized expansion is similar to the expansion observed in many other higher education systems (Levy 2006). Quite simply, higher education expansion in Peru has taken place without an emphasis on either quality or equality (Cuenca 2015a).

Further, the expansion of the higher education system has not benefitted those groups that have been traditionally excluded (Cuenca, 2014b). For instance, while elementary education access is nearly universal, in higher education there are increasing dropout rates among traditionally excluded groups: Quechuas, Aimaras, Amazonans and African-heritage students (Cuenca 2014b). Indigenous youth in Peru have long been excluded (Cuenca 2015b). Furthermore, Cuenca (2015a) calls attention to recent changes in Central-Andean nationsBolivia, Ecuador and Peru—where indigenous and traditionally excluded groups have shifted from rural areas to mid-size or large cities. Such geographic movement is important to investigate further for its impact on educational and labor market opportunities and resulting (in)equality.

Given the unequal distribution of higher education institutions in Peru, where the majority of postsecondary education institutions are located in the capital, Lima, and given the aforementioned demographic changes in the country, geographic mobility is closely related to educational opportunity. Benavides and Etesse (2012) studied intra-national mobility patterns in Peru and concluded that mobility was higher among men than women, and also higher among urban than rural populations.

Despite unequal access, higher education is highly valued among all social groups in Peru. It is identified as a valuable legacy and as a mechanism for social mobility (Cuenca and 
Niño 2011). Thus, it is possible to theorize educational mobility in the Peruvian context on at least two different dimensions. First, this implies geographical relocation where individuals and/or groups move to regions of higher opportunity. Secondly, educational mobility also connotes moving up in income and social status as a result of increased academic preparation and attainment. We assume that these two phenomena-geographic mobility and social mobility — are interconnected, and a primary aim of this study is to explore that connection in the Peruvian context.

Although the specifics of spatial phenomena vary from place to place, country to country, or region to region, nearly all places have ways that geography influences who can access quality education and, therefore, influences social stratification and mobility. To use the United States as an example, there are some "education deserts" (Hillman, 2016) where opportunities simply do not exist for people without moving. Even so, most students attend college close to home (Eagan et al., 2016; Hillman \& Weichmann, 2016), perhaps implying that geography is less relevant. However, the highest quality and most competitive institutions are still likely only to be attended by those willing to move for the opportunity, meaning that access to a high quality education includes a geographic component even in such a context.

A converse aspect of geographic mobility, however, involves reverse mobility. Cuenca $(2012 ; 2014 a)$ conducted a qualitative study of recent college graduates in Peru who benefited from the Ford Foundation International Fellowships Program. While paying attention to many aspects related to their experience of exclusion, the study paid particular attention to mobility and identified that many of the students remained in the same region where they were born. Moreover, many of the students who conducted studies abroad, decided to return to their communities of origin, revealing the complicated nature of space and place as related to education and mobility. Returning to one's community can be positive 
if skills and ideas from the education attained are brought back and shared, but may also have negative consequences for the individual relative to opportunities they could pursue elsewhere.

\section{Conceptual Perspectives}

Given the exploratory nature of this study and the limited existing research on geographic mobility in the Peruvian higher education context, the use of a rigid theoretical framework would be constraining. Therefore, multiple conceptual perspectives inform the analysis and serve to make further theorization possible in future research. Aligned with the Peruvian context and the literature reviewed above, our study is informed by concepts of a) center and periphery, b) push and pull factors in education, including academic attraction; c) quality in higher education (and its relationship to push-pull factors); and d) the geography of opportunity.

\section{Center and Periphery}

The sociological concepts of "center and periphery" (Shils, 1975, p. 4) have been adopted for the study of international mobility in higher education (e.g. Altbach 1981; 1998) but can also inform mobility within a country. In its simplest expression, center and periphery suggest that resources and opportunities are concentrated in proximity to the centers of power in society. This concentration is observable in geographic terms, related to proximity to centers of political power, such as national capitals (Shils, 1975), but also in the centrality of privileged groups in any society.

Center and periphery present important conceptual advantages when studying Peru because they can take into consideration the country's colonial legacy. Colonized nations were placed in peripheral status in relation to their colonizers (Frenkel, 2014) but colonization also involved a process of local and regional reorganization by which peripheral centers were established (Bushnell and Greene 2002). This reorganization has long term 
effects; for instance, Peru's capital, Lima, was the capital of the Spanish colonial province that extended throughout more than half of South America in the $15^{\text {th }}$ Century. Consequently, a center/periphery conceptualization resonates with the complexity of contemporary multicultural Peru characterized by the interplay of Andean, Amazonian and Afro-Peruvian cultures (Greene 2007) located in specific geographic locations, and connects this contemporary complexity with the legacy of colonialism that can still be observed in Peruvian higher education (Cuenca 2015; Galarza and Kogan 2015).

\section{Push and Pull Factors in Educational Mobility}

Studies of student mobility in higher education globally have largely focused on cross-border student mobility. Many of these studies reveal flows from low-income to highincome countries leading to brain drain/exchange (Altbach 2013) or global sorting (Lee and Cantwell 2012). A common way of thinking about such movement internationally is through the lens of push and pull factors (e.g., Becker \& Kolster 2012; Chen, 2007; Mazzarol and Soutar 2002; McMahon 1992). Pushes toward particular countries, cities, or institutions are often the result of personal agency, but are also due to structural or environmental factors in the location of origin such as poor access to higher education institutions, low quality of higher education, prohibitive costs of higher education, or unavailability of particular programs. Pull factors, on the other hand, often have to do with the academic attraction that a particular location has for a student (Kolster, 2010). This attraction may include factors such as higher quality, greater program accessibility, lower costs, greater availability of information about the location/education, or the likelihood of greater returns to education. (For a thorough list of push and pull factors, see Becker and Kolster [2012].)

A limited number of studies have focused on intra-regional mobility. For example, within Europe, Van Mol and Timmerman (2013) theorized a series of elements influencing the decision to move in order to pursue a degree. These elements include the academic 
reputation of the host location (a pull factor) and the economic conditions of the sending location (a push factor). Notably, Van Mol and Timmerman took into consideration students' socioeconomic status and emphasized: "it is often the economically better-off populations who opt for migration" (p. 467). The study of student mobility, therefore, is important beyond understanding where students move, but why they move there, and what the consequences of such movement are not only for individuals, but also for the social inequality.

While international mobility is important in a globalized world, economic globalization has also contributed to the shift from a focus on inequality across borders to greater inequality within borders (Goesling 2001). A similar set of push factors to those discussed at the country level (low number of local institutions, low quality of local institutions) and pull factors (academic attractiveness, higher quality institutions in geographic centers, wider variety of majors) are also salient within Peru. We therefore leverage these international concepts to inform our intra-national examination of geographic mobility for University education within Peru to better understand inequality in that national context.

\section{Quality in Higher Education}

As discussed above, the university expansion in Peru did not increase quality across all parts of the country. The resultant unequal distribution of high quality higher education is likely one of the forces behind student mobility. However, there are many competing definitions of quality and the concept is often confused with compliance and reputation. In order to define quality for the present study, we look closely at the relationship of access and quality. Rather than taking an elitist view (Bergquist, 1995), quality is conceptualized in this study in a broad fashion that takes into consideration equitable access and relevance (Blanco Ramírez \& Berger, 2014). Following Harvey and Newton’s (2007) recommendation that quality must be defined after careful consideration of the local context, we turn to the 
National Superintendence of Higher Education (SUNEDU, 2015), who state that lack of relevance of higher education for citizenship and for the workforce are major quality challenges. Further, Peru's 2014 legislation on universities (Federal Law of Peru 30220) identified universities' social responsibility and their commitment to national development as "the foundation of university life" (p. 527229). In the Peruvian context, therefore, educational quality is intertwined with social and economic development. Institutions of low quality (more likely in the periphery) may push a student to pursue higher education elsewhere. In a complementary way, high quality institutions (most likely the center) may be a pull factor for students. The study of such movement is important for a better understanding of both individual motivations and outcomes, but also national economic and social development.

\section{Geography of Opportunity}

Sociologists and education researchers have long studied educational systems as mechanisms for maintaining or exacerbating inequality, and have a variety of theories and frameworks to explain such phenomena. However, even in these well-developed perspectives, the spatial forces at work in perpetuating such inequality are often ignored (Lobao, Hooks \& Tickamyer, 2007). For this study, therefore, we rely on the concept of the "geography of opportunity" (Galster \& Killen, 1995) to address this gap and inform our study of student mobility. The "geography of opportunity" frames peoples' decision-making processes not as simply the result of their personal characteristics, but as also fundamentally shaped by local opportunity structures. While this perspective has been used to examine issues such as housing (Briggs, 2005) it is less often invoked to discuss education (see Tate, 2008 for an exception). However, as discussed above, the opportunities for quality university education in Peru are not equally distributed geographically. Therefore, the geography of opportunity is appropriate and presents unique ways to understand causes and consequences of student mobility. 


\section{Research Questions}

Given the Peruvian context, the relevant literature, and related conceptual perspectives, we specifically address the following research questions:

1. What proportion of Peruvian university students attended an institution in a region other than where they attended secondary school?

2. To what extent are demographic indicators of inequality (e.g., gender, parental education) related to geographic mobility for university attendance?

3. To what extent does prior geographic mobility predict mobility for university attendance?

4. How do these relationships differ based on the number and quality (i.e., intensity) of universities in a geographic region?

\section{Data and variables}

The 2010 University Census was conducted by Peru's National Institute for Statistics and Informatics (Instituto Nacional de Estadística e Informática, INEI) and the National Assembly of University Rectors. The census was aimed at exploring the demographic, economic and academic conditions of students, faculty, and administrative staff. In addition, the census documented physical plant, equipment, and infrastructure. This 2010 university census, the second to have been conducted in Peru, took place simultaneously with over 780,000 students in 100 universities. 35 of these universities are public and 65 are private. About 4000 students (less than 1\%) were missing data for one of the variables in our study, and were dropped for the analyses, resulting in an analytic sample size of 779,977 .

The main factors that the census recorded related to (a) institutions, (b) undergraduate and graduate students, (c) faculty, (d) administrative and support staff, and (e) campus. These factors focused on different academic units (i.e. colleges, professional schools or graduate schools). In regards to undergraduate students, who are the focus of our study, the census 
focused on variables about identity, demographic characteristics, housing conditions, precollege educational background, academic performance, economic characteristics, research experience, and migration. Overall, this dataset is quite powerful given the rarity of a national census of university students with such rich information available.

\section{Methods}

To address our first research question we used descriptive analyses. We created a variable indicating whether a student attended secondary school and university in two different regions, to measure geographic mobility for university attendance. We then measured the proportion of university students who were mobile according to this definition, as well as descriptive statistics for all other variables overall and separately by region.

To address our second research question, we used logistic regression, with the total population of university students in Peru. The dependent variable for these regression models was our binary indicator of geographic mobility: whether a student attended secondary school in a different region than where they attended university. We used a set of available independent variables that represented social indicators of inequality in Peru: gender, parental education, disability, parenthood, and financial dependence.

To address our third research question related to students' prior mobility, we added an additional independent variable to this regression model. The measurement of prior geographic mobility was a dummy variable indicating whether a student attended secondary school in a different region then where they were born. In other words, geographic movement between birth and secondary school is considered "prior mobility."

We also included dummy variables for each region (using Lima as the reference) in the existing regression model. This cross-sectional fixed-effects model has two useful features. First, the coefficients for each independent variable in this model effectively become within-region estimations rather than combinations of within- and between-region influences, 
meaning that fixed, unobservable characteristics that could explain differences between regions, but which are not available as variables, are controlled. Second, the coefficients for each regional dummy variable provide another comparison of the geographic mobility of university students in that region, relative to those in Lima.

To address our final research question, we separated the regression analyses into three subgroups based on the university "intensity" in each region. Using expert local knowledge, we categorized each region where a student had attended secondary school as low, medium, or high university intensity. Intensity is defined as a combination of the number and quality of institutions in the region. We ran our final regression model described above - including individual factors, prior mobility, and region-level dummy variables - for each of the three intensity groupings of regions, and compared results across the groups.

As with all secondary data analysis, there are limitations to this study. We are limited by the variables available in this dataset, and therefore are subject to omitted variable bias. For example, ethnicity is a marker of inequality we would prefer to use in our models, but which is not available in the dataset. In addition, these data can only tell us one particular story about students that already attend university. We cannot fully understand the role of geographic mobility and inequality in relation to whether one is able to attend university with these data. Nonetheless, this study can begin to paint a picture of these phenomena in Peru.

\section{Results}

Means and standard deviations for each variable, overall and by region, are given in Table 1. In response to the first research question, overall about $13 \%$ of University students attended secondary school in a different region from where they attended university. In other words, these students were geographically mobile for university attendance. However, this varies greatly by region. Only about $4 \%$ of university students who attended secondary school in the Lima region went to another region for university. On the other end of the 
spectrum, for university students who had attended secondary school in Amazonas, about two-thirds left the region for university attendance. In additional analyses (not shown, available on request), origins and destinations of students were explored further; the regions where students attended university were cross-tabulated with the region where they attended secondary school. This confirmed that about a third (34\%) of university students who attended secondary school in Amazonas region, stayed in Amazonas for university. However, it also showed that nearly as many students (25\%) moved from Amazonas to the Lima region to attend university — a move from the periphery to the center of Peru.

Logistic regression models are presented in Table 2. The first column shows odds ratios for each inequality indicator in predicting university attendance in a different region than where one attended secondary school. Odds ratios are interpreted as showing a positive relationship if greater than one, and a negative relationship if less than one. (Statistical significance is only reported at the $\mathrm{p}<.001$ level given our very large sample size.) As an example, females had odds of being geographically mobile for university attendance that were about $80 \%$ of the odds for males; on average, males were more geographically mobile,. In contrast, looking at model 1 in Table 2, a student whose mother had earned a university degree had odds of being in a different region for university than for secondary that were about 1.1 times greater than the odds of a student whose mother had no college (reference group). Along with the other variables related to parental education in Table 3, this indicates that students whose parents had university degrees were more geographically mobile, on average, than other students when pursuing university education.

In the second model in Table 2, a student's prior geographic mobility was added as a predictor. This variable was highly predictive of mobility for university attendance. Among university students, those who had moved earlier in their lives had odds of moving to attend university that were three times higher than other students. This aligns with earlier findings 
(Bonin 2008) and may suggest a type of cumulative advantage related to geographic mobility whereby inequality is maintained or exacerbated. However, prior mobility can be complicated by the child's age or by the specific purposes of such mobility, so more research would be needed to confirm this (Tonnensen, Telle and Syse 2016).

Interestingly, in both models 1 and 2, having dependents, being financially independent, and having a disability were all related to greater odds of geographic mobility for university attendance. Students who were financially independent may have been more mobile due to significant wealth, rather than due to just making ends meet by working, and therefore may have been more mobile. Results for the other groups are less clear. It is possible that because our sample consisted of individuals that had already succeeding in making it to university, that students with disabilities in this category would have needed to move simply to have their needs met. If these students had not moved, they may not have had appropriate university options, which could explain the positive relationship between this variable and mobility.

The third model in Table 2 includes region-level dummy variables. The interpretation of the coefficients in this model can be considered as within-region coefficients. With Lima as the reference group, these coefficients can be interpreted as the odds of having moved across regional boundaries to attend university, relative to those who attended secondary school in Lima. Not surprisingly (and in alignment with results in Tables 1 and 2) students from all other regions were more likely to have moved for university attendance in comparison to Lima secondary students. Again, however, there is significant variation. University students who attended secondary school in Amazonas region had odds of being mobile that were nearly 60 times greater than those who attended secondary school in Lima, whereas those in Arequipa region only had odds of mobility about twice as large as those attending secondary school in Lima. 
These finding are logical and consistent in one way, yet potentially confusing in another. It makes sense that for a secondary student from Amazonas, a region that has few university options, to succeed in pursuing university, she will be more likely to need to leave the region. However, this region is also remote, relatively poor, with a disproportionately large population of marginalized people for whom geographic mobility is a great challenge. Simultaneously, therefore, mobility for university attendance is more necessary for students in such regions and yet these regions have populations who are less likely to be mobile based on other indicators of inequality. The "push" factors of the local disadvantaged region are likely in tension with other limitations created by the geographical structure of opportunity.

To examine these contradictory phenomena, and in response to our final research question, we look at the descriptive and logistic regression results separately by the university intensity of the region where a student attended secondary school. Based on the number and quality of institutions, we categorized the regions into those with low, medium, and high university intensity. Regions with low numbers or quality of institutions are Amazonas, Apurimac, Huánuco, Madre de Dios, Moquegua, Pasco, San Martín, Tumbes and Ucayali. Those with medium numbers or quality of institutions are Ancash, Ayacucho, Cajamarca, Huancavelica, Ica, Junín, Loreto, Puno and Tacna. Those with high numbers or quality of institutions are Arequipa, Cusco, Lambayeque, La Libertad, Lima and Piura. Descriptive results separated by this distinction are presented in Table 3; logistic regression results separated this way are in Table 4.

In Table 3, it is instructive to simply look at the number of observations in each category. Of the nearly 800,000 university students in Peru, a little over 60,000 (about 8\%) attended secondary school in a region with low numbers and/or poor quality of universities. About $30 \%$ had attended secondary school in medium-intensity regions, and the remaining $62 \%$ attended secondary school in a region with high numbers and or quality of universities. 
This is a reminder of the geographic differences of attending university based on core and periphery distinctions within the country. Additional results in Table 3 show how other factors in our study differ by the university intensity of the region where students attended secondary school.

From Table 4, it is apparent that the relationships between demographic indicators of inequality and geographic mobility for university vary by group. In general, students who attended secondary school in low or medium intensity regions had similar dynamics, but students who attended secondary school in high-intensity regions looked different in some ways. Females were less likely to be geographically mobile in all contexts (with odds of mobility that are between .82 and .86 the odds of males). However, the role of parental education differed significantly. In regions with low or medium university intensity, any level of university education by either parent predicted that the student was more likely to be geographically mobile for university attendance (odds ratios varied from 1.08 for a father with some University education in a medium-intensity region, to 1.83 for a mother with a University degree in a low-intensity region). In other words, families who are advantaged based on prior parental education could maintain or increase their advantage by being geographically mobile when their immediate context offered fewer educational opportunities (i.e., low- or medium intensity of universities).

For students in high-intensity regions, however, the role of parental background is not positively related to mobility (odds ratios all less than one). In other words, having more and higher quality universities accessible in a region diminishes the role that parental education and geographic mobility play in propagating inequality through university education. Interestingly, however, there is a small negative relationship (coefficients of .86 and .90) between mobility and parents having "some" university, but not a degree. 
Whether a university student had dependents was also quite different across the three groups. Compared to those without dependents, students with dependents from low-intensity regions were less likely to move for university (odds of mobility were .88 of those without dependent), those in medium-intensity regions were no different, and those in high-intensity regions were more likely to move to attend university (odds of mobility were nearly 1.5 times higher than those without dependent). This finding is complicated, but shows that the interaction between an individual's characteristics, the university infrastructure in a given region, and geographic mobility, can play out in very different ways and must be considered.

\section{Discussion and Implications}

The initial objective of this exploration was to better understand the connection between geographic mobility for university attendance and inequality in Peru. However, the interpretation of these results also leads to implications for additional inquiry more broadly, beyond Peru. Below we discuss the results in terms of Peru specifically, for other higher education contexts globally, and for future conceptual and empirical work related to our topics.

\section{Peruvian Higher Education}

Our results reveal that geographic mobility in pursuit of higher education is related to individuals' sociodemographic characteristics in Peru. This can be seen as our primary level of analysis. For example, female university students were consistently less likely to have moved from where they attended secondary school in order to attend university. This finding implies that gender is a continued marker of inequality in relation to geographic mobility, and therefore also in relation to university attendance and related social mobility. This finding is particularly interesting given that gender parity in higher education has been reached when considered broadly in Peru. Thus, the role of gendered mobility would benefit from more 
research to understand why mobility does not follow more modern gender trends and how women have achieved gender parity with lower rates of mobility.

The other main finding at the primary level of analysis is that, as predicted by pushand pull-factors, students in the peripheral areas are more likely to have moved geographically if they reach university. These areas tend to be more isolated and experience greater poverty, which may lead to the speculation that students with lower socioeconomic status are more likely to move. However, we do not have a direct measure of SES, so more research would be needed to make that claim. Additionally, all of our results must be interpreted in light of the sample - this is a study of mobility for students that already succeeded in making it to university.

While the direct effects of sociodemogrpahics and region provide insight into who is more likely to move within Peru, combining these factors to examine within-country geographic variation of educational opportunity constitutes a second level of our analyses, and is perhaps our more interesting contribution to the literature. Results show that some of the demographic factors identified in the first level of analysis do not operate in the same way in all regions. Depending on the (high, medium or low) availability of universities and their quality, associations between inequality indicators and geographic mobility change. For example, in regions with limited postsecondary options (i.e., areas with significant push factors), having a parent with a university degree is highly predictive of a student leaving that area to pursue higher education in another region. However, parental education does not serve as such a mechanism for advantage (at least related to geographic mobility) when the region has a high number and quality of university options (a lesser degree of push factors).

Based on these results, two important conclusions can be reached. First, characteristics of regions are important in explaining the variation in relationships between inequality and mobility for university education. Furthermore, sociodemographic 
characteristics alone cannot explain differences in mobility patterns in Peru. Secondly, we conclude that one valuable strategy to explain such differences is analyzing cross-region interactions, particularly the availability and quality of higher education institutions in the region as features of academic attractiveness, in addition to sociodemographic variables. Such approaches can likely be adapted from this study of Peru to apply to studies of mobility and inequality in other countries or regions.

\section{Other higher education contexts}

Even though the present study focuses exclusively on Peru, its implications may extend to other national contexts where educational opportunity is unevenly distributed or where the private sector has absorbed a significant proportion of higher education expansion. The results may be of particular interest for other nation-states in Latin America that experience significant levels of internal inequality and/or geographic mobility. These results may also have implications for other regions of the world where educational opportunity has been concentrated in historically important geographical centers as a result of colonization. Large and diverse higher education systems fall in this category, including Brazil, India and Mexico, but we can point to vast areas of sub-Saharan Africa and South East Asia where these questions are also salient.

Additionally, the concepts we have relied on and the type of analysis we have used are likely relevant to countries even more broadly, including the global North. The ways that students move within a country for higher education opportunity would be particularly relevant for nations that have certain types of institutions, or certain types of majors, concentrated in particular geographic regions. At times, such unequal geographic distribution of higher education may occur as an unintended consequence of other policies. A variant of this framework could be used, for example, to analyze the ways Excellence Initiatives in various countries (e.g., Cheng, Wang and Liu 2014) may shift the geographic distribution of 
opportunity, and how that could affect mobility and inequality. For all of these global possibilities, while past scholarship has focused on international or cross-border mobility in relation to inequality (Maldonado-Maldonado 2014; Marginson and Sawir 2005), this study illustrates that geographic mobility and social inequality can also be analyzed from an intranational perspective.

\section{Future Research}

This study was framed conceptually with multiple perspectives and our results lead to future directions in the development of these concepts and their application to future studies, both in Peru and beyond. Given the exploratory nature of this paper and the lack of similar research in Peru, more research should be conducted, preferably with data that begin with students prior to university attendance and follow them longitudinally. This would overcome the limitations of using a snapshot of university students and relying on retrospective measures of their geographic mobility. Data from the National Household Survey (Encuesta Nacional de Hogares) are particularly promising in this regard. With alternate data, future research should also explore alternate definitions of mobility (e.g., short- versus long-term mobility). Extended analyses connecting educational mobility to longer-term mobility for employment, for example, would be worthwhile. Future studies should also run alternate analyses with and without Lima given its very unique status in the country, and map findings using GIS including more spatially nuanced analyses.

Additionally, our data were not able to directly address a number of indicators of inequality, which could reinforce the picture of mobility and inequality emerging from this study, but which could also reveal different patterns and mechanisms of inequality in Peru. Importantly, we were not able to examine ethnicity as a factor of inequality. Future research should address this question directly and try to understand how ethnicity, language, and/or indigenous status are related to mobility and education. How might these be related to 
educational mobility? Why might they be unique? Are push and pull factors different for various sub-populations within Peru? Finally, while we have examined mobility by region, there are also other ways of considering regional differences, which could be defined by aggregate ethnicity or sociodemographic factors.

A better understanding of which indicators of inequality are associated with greater mobility can ultimately lead to policies targeting disadvantaged groups, or policies that differentiate according to such disadvantage. At the regional level, there may be future implications for new university construction, transportation, and other macro-level factors. In particular, future research on this topic could provide valuable input for new decisions the Peruvian government needs to make about quality assurance in terms of licensure and accreditation. These decisions will impact how academic offerings are made available and distributed.

Several things about our analytic approach can also be adapted and leveraged for future research in other contexts and regions beyond Peru. The notion of center/periphery was useful as a framework for our exploratory study, and indeed the prominence of Lima in our results supported this perspective. However, this heuristic has significant limitations in capturing the complexity of mobility, inequality, and identity. The center/periphery binary, for instance, fails to capture the reality that students may simultaneously hold central and peripheral ascription in regards to different areas of their identity. Urban women or rural nonindigenous populations illustrate these complex relations. Such complexities should be explored in further inquiry, and research in various locations could lead to greater insight about using this lens for such research.

Our research leads to a number of interesting questions related to why the varied mobility patterns that we've uncovered exist, and how they may manifest themselves uniquely for various populations. Why are women less likely to have moved across regions to 
attend university? Why does parental education differ in its salience for mobility and particularly how might this differ for maternal versus paternal education? How do any of these questions differ for marginalized ethnic groups (which were not able to be represented in this study)? Finally, while we briefly speculate about the mobility of students after a university education, issues of place attachment, brain drain, and regional economic development are beyond the scope of this study will be valuable in future research.

While this study surfaced an interesting set of findings, the real benefit may be generating a larger set of questions that can examine geographic and social mobility through new lenses. Some of these questions could be explored through different methodological approaches. Qualitative or mixed-method approaches might reveal some of the meanings associated with mobility to complement the identification of patterns achieved in this project.

We have framed the geography of opportunity as one possible explanation for the differences in mobility patterns from various regions of the country. However, this too leads to intriguing questions for nearly any context. Why are certain opportunities related to certain geographies? What are the political and social processes that have lead to those spatial phenomena and related inequalities? How can other frameworks not only reveal nuanced understandings of power and oppression related to geography but also lead to changing those structure that propagate such practices? Soja's (2010) conception of "spatial justice" may be particularly useful in this regard. Rather than just being a conceptual tool, spatial thinking can also be integrated more fully into the methods for future research; "the consideration of the relative locations of social phenomena, the causes of the locational pattern, and the pattern's consequences" (Logan, 2012, p. 509) is a logical next step in this line of research.

Other more traditional non-spatial perspectives may also be useful to integrate in meaningful ways with spatial lenses, including those directly focused on inequality and educational outcomes. These may include cumulative advantage (DiPrete and Eirich 2006), 
Maximally Maintained Inequality (MMI; Raftery and Hout 1993) or Effectively Maintained Inequality (EMI; Lucas 2001 2009). Concepts such as horizontal inequality (Stewart, 2008) and dynamic inequality (Fitoussi and Rosanvallon, 2010) may also serve as useful frameworks moving forward. Such future research has the potential to provide a more thorough and nuanced picture of mobility, higher education, and inequality in Peru and potentially around the world.

\section{References}

Altbach, P. (1981). The university as center and periphery. The Teachers College Record, 82(4), 601-621.

Altbach, P. G. (1998). Comparative higher education: Knowledge, the university, and development. Westport, CT: Greenwood.

Altbach, P. G. (2013). Brain drain or brain exchange? In The International Imperative in Higher Education (pp. 41-45). Rotterdam, Netherlands: Sense Publishers.

Becker, R. \& Kolster, R. (2012). International student recruitment: Policies and developments in selected countries. The Hague: Netherlands Organisation for International Cooperation in Higher Education (Nuffic).

Benavides, M., León, J., Haag, F. \& Cueva, S. (2015). Expansión y diversificación de la educación superior universitaria, y su relación con la desigualdad y la segregación. Lima: GRADE.

Benavides, M. \& Manuel Etesse, M. (2012). Movilidad educativa intergeneracional, educación superior y movilidad social en el Perú: evidencias recientes a partir de encuestas a hogares. In, Cuenca, R., ed., Educación superior, movilidad social e identidad. (pp. 51-92). Lima: IEP.

Blanco Ramírez, G. \& Berger, J. B. (2014). Rankings, accreditation and the international quest for quality: Organizing and approach to quality. Quality Assurance in Education, 22(1), 88-104. doi: 10.1108/QAE-07-2013-0031

Bonin, H, et al (2008). Geographic mobility in the European Union: Optimizing its economic and social benefits. Bonn, DE: Institute for the Study of Labor (Institut zur Zukunft der Arbeit).

Briggs, X. N. D. S. (2005). The geography of opportunity: Race and housing choice in metropolitan America. Brookings Institution Press. 
Brunner, J.J. (2011). Gobernanza universitaria: tipología, dinámicas y tendencias. Revista de Educación, 355, 137-159.

Galster, G. C., \& Killen, S. P. (1995). The geography of metropolitan opportunity: A reconnaissance and conceptual framework. Housing Policy Debate, 6(1), 7-43.

Lobao, L. M., Hooks, G., \& Tickamyer, Ann R. (Eds.). (2007). The sociology of spatial inequality. Albany, NY: SUNY Press.

Bergquist, W. H. (1995). Quality through access, access through quality. San Francisco: Jossey Bass.

Bushnell, A. T., \& Greene, J. P. (2002). Peripheries, centers, and the construction of Early Modern American Empires. In C. Daniels \& M. Kennedy (Eds.), Negotiated Empires. (pp. 1-14). New York: Routledge.

Chen, L.H. (2007). East-Asian students' choice of Canadian graduate schools. International Journal of Educational Advancement, 7(4), 271-306.

Cheng, Y., Wang, Q., \& Liu, N. C. (2014). How world-class universities affect global higher education: Influences and responses. Springer.

Cuenca, R. (2015a). Entre la democratización del acceso y la precarización del servicio. La masificación universitaria en el Perú. Una introducción. I, R. Cuenca (Ed.), La educación universitaria en el Perú: Democracia, expansión y desigualdades. (pp.917). Lima: IEP.

Cuenca, R. (2015b). Higher education for Latin America: Two challenges in a field of opportunities. In, V. Stead (Ed.), International Perspectives on Higher Education Admission Policy: A Reader. (pp.74-82) New York: Peter Lang Publishing.

Cuenca, R. (2014a). An "other" social mobility, viewed from the standpoint of exclusion. Excellence in Higher Education, 5, 14-25.

Cuenca, R. (2014b). La educación superior en el Perú: expansión, calidad e inclusión. In, J.J. Brunner y C. Villalobos (Eds.), Políticas de educación superior en Iberoamérica, 2009 - 2013. Santiago de Chile: Universidad Diego Portales.

Cuenca, R. y Niño, R. (2011). Igualando oportunidades. Sistematización del Programa Internacional de Becas de la Fundación Ford en el Perú. Lima: IEP

Cuenca, R., \& Patiño, P. (2014). Profesionalización femenina desde los márgenes: Trayectorias de mujeres indígenas hacia la educación superior. En, S. Vargas, (Comp.), Bajo el radar de Sofía. Oportunidades y barreras de las profesionales en el Perú (pp. 77-107). Lima: IEP.

Cuenca, R., \& Ramírez, A. (2015). ¿Interculturalizar la universidad o universalizar la interculturalidad? Sistema universitario y población indígena. In R. Cuenca (Ed.), $L a$ educación universitaria en el Perú: Democracia, expansión y desigualdades (pp.59104). Lima: Instituto de Estudios Peruanos. 
Cuenca, R. \& Reátegui, L. (2016). La (incumplida) promesa universitaria en el Perú. Lima: IEP.

Dargent, E. y Chávez, N. (2016). ¿Extraer para educar? Boom de commodities.

Construcción estatal y universidad pública. Lima: Pontificia Universidad Católica del Perú.

de Belaunde, C., Trivelli, C., \& Israel, C. (2011). Inclusión a través de la educación de posgrado: El programa internacional de becas de la Fundación Ford. Lima: Instituto de Estudios Peruanos.

DiPrete, T. A., \& Eirich, G. M. (2006). Cumulative advantage as a mechanism for inequality: A review of theoretical and empirical developments. Annual Review of Sociology, 32, 271-297.

Eagan, K., Stolzenberg, E. B., Bates, A. K., Aragon, M. C., Ramirez Suchard, M., \& RiosAguilar, C. (2016.) The American Freshman: National Norms Fall 2015. Los Angeles: Higher Education Research Institute.

Fitoussi, J.P. \& Rosanvallon, P. (2010), La nueva era de las desigualdades. Buenos Aires, Manantial.

Frenkel, M. (2014). Can the periphery write back? Periphery-to-centre knowledge flows in multinationals based in developing and emerging economies. In R. Westwood (Ed.), Core-periphery relations and organization studies (pp. 33-52). New York: Palgrave Macmillan.

Garfias, M. (2011). La investigación en la universidad pública regional y los fondos del canon, 2004-2008. Lima: Instituto de Estudios Peruanos.

Goesling, B. (2001). Changing income inequalities within and between nations: New evidence. American Sociological Review, 66, 745-761.

Greene, S. (2007). Entre lo indio, lo negro, y lo incaico: The Spatial Hierarchies of Difference in Multicultural Peru. The Journal of Latin American and Caribbean Anthropology, 12(2), 441-474.

Harvey, L. \& Newton, J. (2007). Transforming quality evaluation: moving on. In D. Westerheijden, M. Rosa, \& B. Stensaker (Eds.), Quality Assurance in Higher Education Trends in Regulation, Translation and Transformation (pp. 225-245). Dordrecht: Springer.

Hillman, N. W. (2016). Geography of college opportunity: The case of education deserts. American Educational Research Journal, 2831216653204. https://doi.org/10.3102/0002831216653204

Hillman, N. \& Weichmann, T. (2016). Education deserts: The continued significance of place in the twenty-first century. Washington DC: ACE. 
Kolster, R. (2010). Academic attractiveness of countries to students: Explaining and measuring a countries' academic X factor. Oslo: University of Oslo, Institute for Educational Research, Retrieved from: https://www.duo.uio.no/handle/10852/30477

Lee, J. L., \& Cantwell, B. (2012). The global sorting machine: An examination of neoracism among international students and postdoctoral researchers. In B. Pusser, K. Kempner, S. Marginson,\& I. Ordorika (Eds.), Universities and the Public Sphere: Knowledge Creation and State Building in the Era of Globalization (pp. 47-63). New York: Routledge.

León, J., \& Sugimaru, C. (2013). Entre el estudio y el trabajo: Las decisiones de los jóvenes peruanos después de concluir la educación básica regular. Lima: Grupo de Análisis para el Desarrollo.

Logan, J. R. (2012). Making a place for space: Spatial thinking in social science. Annual Review of Sociology, 38(1), 507-524. https://doi.org/10.1146/annurev-soc-071811145531

Lucas, S. R. (2001). Effectively maintained inequality: Education transitions, track mobility, and social background effects. American Journal of Sociology, 106(6), 1642-1690.

Lucas, S. R. (2009). Stratification theory, socioeconomic background, and educational attainment. Rationality and Society, 21(4), 459-511.

Maldonado-Maldonado, A. (2014). Academic mobility as social mobility or the point of no return. In The Forefront of International Higher Education (pp. 127-137). Springer Netherlands.

Marginson, S., \& Sawir, E. (2005). Interrogating global flows in higher education. Globalisation, Societies and Education, 3(3), 281-309. http://doi.org/10.1080/14767720500166878

Mazzarol, T. \& Soutar, G.N. (2002). 'Push-pull' factors influencing international student destination choice. International Journal of Educational Management, 16(2), 82-90.

McMahon, M. E. (1992). Higher education in a world market. Higher Education, 24(4), 465482.

Raftery, A. E., \& Hout, M. (1993). Maximally maintained inequality: Expansion, reform, and opportunity in Irish education, 1921-75. Sociology of Education, 66(1), 41-62.

Shavit, Y., Arum, R, \& Gamoran, A. (2007). Stratification in higher education: A comparative study. Stanford University Press.

Shils, E. (1975). Center and periphery: Essays in macrosociology. Chicago: University of Chicago Press.

Stewart, F. (2008). Horizontal inequalities and conflict: An introduction and some hypotheses. En F. Stewart (ed.). Horizontal Inequalities and Conflict: Understanding 
Group Violence in Multiethnic Societies. Oxford: Centre for Research on Inequality, Human Security and Ethnicity.

Superintendencia Nacional de Educación Superior Universitaria. (2015). Informe de gestión institucional [2015 Annual report of the National superintendence of higher education]. Lima: SUNEDU.

Tønnessen, M., Telle, K., \& Syse, A. (2016). Childhood residential mobility and long-term outcomes. Acta Sociologica, 59(2), 113-129.

http://doi.org/10.1177/0001699316628614

Van Mol, C., \& Timmerman, C. (2014). Should I stay or should I go? An analysis of the determinants of intra-European student mobility. Population, Space and Place, 20(5), 465-479.

Yamada, G., Castro. J. F., Bacigalupo, J. L., \& Velarde, L. (2013). Mayor acceso con menor calidad en la educación superior: Algunas evidencias desde las habilidades de los estudiantes. Apuntes, 40(72), 7-32. 